\title{
Estar de a dos para estar de a uno, estar de a uno para estar de a dos ${ }^{1}$
}

Comentario a "¿Por qué Edipo?" (Christopher Bollas, en Ser un personaje. Psicoanálisis y experiencia del sí-mismo. Buenos Aires: Amorrortu, 1994. [Original de 1992])

\section{Realizado por María Consuelo Antúnez²}

Leer el texto de Bollas (1994) sobre el Edipo no estuvo exento de complejidad, primero por mi ignorancia sobre los detalles histórico-dramáticos que componen la obra de Sófocles, y luego, por lo difícil que me ha sido en todos mis años de estudio comprender e integrar la metáfora freudiana sobre el complejo de Edipo. Hay algo que simplemente no termina de hacerme sentido y honestamente no creo que lo haga. Sin embargo, la comprensión que presenta Bollas sobre el Edipo, o bien, la relectura que elabora, ofrece algo que me parece muy novedoso y que por primera vez me acerca un poco a comprender o darle algo más de sentido a la metáfora edípica.

Según Bollas (1994), el niño resuelve el dilema edípico gracias a un descubrimiento generado por sus angustias y deseos. El impulso genital del niño lo lleva a ver a su madre como un objeto de deseo diferente y a su padre como rival. Así, reconoce su lugar en esta tríada al entender que su padre lo precedió en su relación con su madre. Aparece el temor al padre pero también el amor a él, la identificación con él y el consecuente sentimiento moral de que el acceso erótico a la madre tiene algo de inadecuado (Bollas, 1994). Así podemos ver que, a diferencia de Freud, no se centra solo en el temor, sino en el amor y el reconocimiento del otro, lo cual se asemeja a lo planteado por Lacan en relación a la introducción de la ley del padre y cómo a través de ella aparece por vez primera el deseo del otro. La madre desea a alguien que no es el niño, por lo tanto, ya no son una díada sino una tríada que complejiza la relación y el mismo existir.

Vemos entonces que la angustia de castración no sería lo único que llevaría al niño a diferenciarse, sino también sus deseos y el reconocimiento de los deseos de otros. Estaría, dice Bollas (1994), entre dos órdenes inconscientes profundos (su mente y la del grupo) que quiebran la cohesión simbiótica y edípica. Las estructuras psíquicas relativamente simples del niño, edificadas en torno a situaciones diádicas y tríadicas, son suplantadas por el reconocimiento de la complejidad mental. En esa línea, el niño se convierte él mismo en un

\footnotetext{
${ }^{1}$ Antúnez, M.C. (2018). Estar de a dos para estar de a uno, estar de a uno para estar de a dos. Clínica e Investigación Relacional, 12 (2): 402-404. [ISSN 1988-2939] [Recuperado de www.ceir.info ] DOI: 10.21110/19882939.2018.120215

2 Programa de Máster en Psicoterapia Psicoanalítica Relacional de Ágora Relacional, IPR, Madrid. CeIR Vol. 12 (2) - Junio 2018 ISSN 1988-2939 - www.ceir.info

(c) Derechos reservados/Copyright de Clínica e investigación Relacional y los autores. Prohibida la reproducción total o parcial sin autorización expresa. Este material es para uso científico y profesional exclusivamente y puede contener información clínica sensible. Los editores no se responsabilizan de los contenidos de los autores. Dirigir las consultas sobre derechos y autorizaciones a ceir@psicoterapiarelacional.es
} 
complejo de Edipo, va reflexionando sobre la diferencia entre los humanos y la imposibilidad de llegar al otro a través de la omnipotencia, a la vez que va descubriendo su propia singularidad, dicho de otro modo, se encuentra con la soledad de su propia subjetividad (Bollas, 1994).

Cuando no somos capaces de tolerar la complejidad aparece la angustia, y una de las formas de lidiar con ella, según Bollas (1994), serían las regresiones transformadas, es decir, el movimiento que hacemos al buscar relaciones pareja o amigos íntimos que nos libren de la angustia de significa participar de un grupo y el caos psicótico que este implica. Caos que se ve reflejado en la complejidad de nuestra propia mente, que al volverse intolerable nos llevaría a una regresión para sobrevivir: matrimonio o asociación de dos. Volvemos, en ese sentido, a la calidez pre edípica, antes de caer presos del solitario reconocimiento de nuestra propia subjetividad (Bollas, 1994).

Esto último podría vincularse a lo que plantea Winnicott sobre la capacidad de estar solo, no solo físicamente sino también de la experiencia interna y subjetiva de estar solo, sea en compañía de otros, o no. Esto constituye uno de los signos más importantes de madurez en el desarrollo emocional, y proviene de la capacidad de estar solo en la infancia en presencia de la madre. Si las cosas van bien, dice Winnicott, esta función auxiliar de la madre será internalizada pudiendo dejar de depender de manera absoluta de la función materna (Abello, 2011). En ese sentido, uno podría pensar que si se alcanza esta madurez emocional, no sería necesaria la regresión que propone Bollas, en tanto el reconocimiento de nuestra propia subjetividad no tendría una connotación angustiante. Pero para que esto sea posible, se tiene que haber internalizado adecuadamente la función auxiliar de la madre, lo cual implica que habría que estar de a dos para poder estar de a uno y estar de a uno para luego volver a estar de a dos, he ahí la paradoja.

Por otra parte, pienso que esta asociación de dos que plantea Bollas no tendría por qué constituir un movimiento regresivo si es que las personas que componen esa díada tienen la experiencia de estar solos. Pues esta experiencia sería una condición indispensable para que el infante pueda descubrir su propia vida personal (Abello, 2011). Pero si el adulto no ha tenido la posibilidad de descubrir su mundo interno y desarrollar su propia vida de manera espontánea y creativa, no sería posible compartirla con otro. De modo que aquella asociación constituiría efectivamente una vuelta a la simbiosis más que una relación tercerizada y compleja donde se acepte la diferencia, el deseo del otro y la propia castración. Lo que quiero decir es que una relación de intimidad genuina o asociación de dos madura es aquella en la que se pueda tolerar el espacio intermedio entre 
uno mismo y el otro, que es y será siempre tremendamente complejo, cambiante e impredecible, pero sin el cual no es posible compartir dos mundos sin sacrificar uno de ellos.

\section{REFERENCIAS}

Abello, A. (2011). Desarrollo emocional temprano. Cap. Il de la obra de: A. Abello y A. Liberman Una introducción a la obra de D.W. Winnicott. Madrid: Ágora Relacional

Bollas, C. (1994). Capítulo 10, "¿Por qué Edipo?", en Ser un personaje. Psicoanálisis y experiencia del sí-mismo. Buenos Aires: Amorrortu. [Original de 1992]. 